\title{
Mensinergikan Nilai-nilai Keagamaan dengan Kearifan Lokal sebagai Upaya Mewujudkan Masyarakat Madani (Studi Kasus Komunitas Keagamaan Kejawen di Desa Bajulan Kecamatan Loceret Kabupaten Nganjuk)
}

\author{
Siti Makhmudah \\ Sekolah Tinggi Agama Isalam Miftahul 'Ula
}

\begin{abstract}
This research executed in Countryside of Bajulan of Subdistrict Loceret of Regency Nganjuk. A lot of society assuming, that Countryside Bajulan very go together the mistical things like ritualritual kejawen that is nyadranan, clean countryside, ceremony of parna prahista, kirab pusoko and arca, ritual malem syuro, holy ritual water intake, ritual take a bath in source water, medium of lelaku ritual/meditating, ceremony of ngangsu kaweruh, and others. The Ritual-ritual not get out of the belief kejawen, like shalat at the same time sit, not execute the fasting ramadhan but following feast day of Ramadan and others. This research use the method qualitative (qualitative approach), in the form of utterance or article and behavior perceived the. Research type used is case study, that is a research conducted intensively, inch, and circumstantial to an organization, institute, or certain symptom. Procedure of data collecting with the interview, observation, and documentation. Analyse the data conducted by data discount, data presentation, and conclusion withdrawal. Checking of data Authenticity use the lengthening of taking part in, perception assidinity, and trianggulasi. With the the method applying, expected to make Islam as acceptable majority religion by society of Countryside Bajulan.
\end{abstract}

Keyword: religious values wisely is local, society madani

Copyright (C) 2017 IICET (Indonesia) - All Rights Reserved

Indonesian Institute for Counseling, Education and Theraphy (IICET)

\section{PENDAHULUAN}

Sebelum masuknya agama-agama ke bumi Indonesia termasuk Islam, masyarakat Indonesia dikenal sebagai penganut animisme dan dinamisme. Selain itu, sebelum masuknya agama Islam masyarakat Indonesia telah menganut agama Hindu-Budha.Oleh karena itu, ketika masuk agama Islam komunikasi antara ketiga unsur antar kepercayaan animisme-dinamisme, Hindu-Budha dan ajaran agama Islam yang baru dalam kehidupan mereka tidak dapat dihindarkan. Dalam interaksi ini mereka memiliki latar belakang budaya yang berbeda akibat dari bedanya ajaran agama masing-masing.

Dengan demikian para pembawa agama Islam yang oleh para sejarahwan dikatakan sebagai "pedagang dari Gujarat" dalam menyebarkan agama Islam telah mengalami komunikasi dan interaksi yang intensif dengan penduduk lokal yang telah memeluk agama Hindu-Budha, yang tentu saja karena ajaran agama ini menciptakan kebudayaan yang berbeda dengan kebudayaan pembawa ajaran agama Islam tersebut. 
Unsur budaya Islam tersebar di Jawa seiring dengan masuknya Islam di Indonesia secara kelompok dalam masyarakat Jawa telah mengental unsur budayanya. Islam sejak mereka berhubungan dengan pedagang yang sekaligus menjadi mubaligh pada taraf penyiaran Islam yang pertama kali. Pada awal interaksinya kebudayaan-kebudayaan ini akan saling mempengaruhi baik secara langsung atau tidak langsung dan pada akhirnya kebudayaan yang berbeda ini berbaur saling mempengaruhi antara budaya yang satu dan budaya yang lain. Sehingga, saat Islam sudah memiliki banyak pengikut dan legimitasi politik yang cukup besar, dengan sendirinya kebudayaan Islam-lah yang lebih dominan dan melebur dalam satu kebudayaan dalam satu wajah baru.

Unsur kebudayaan Islam itu di terima, diolah dan dipadukan dengan budaya Jawa. Karena budaya Islam telah tersebar di masyarakat dan tidak dapat di elakkan terjadinya. Pertemuan dengan unsur budaya Jawa, maka perubahan kebudayaan yang terjadi selama ini ada yang masih dapat menjaga identitas budaya Jawa yakni dengan akulturasi.

Menelisik sejarah Jawa yang menjadi tempat untuk didatangi bangsa-bangsa lain, dan kemudian menjadi tempat penyebaran dan tumbuh kembangnya agama-agama besar dunia, maka membuktikan bahwa budaya dan peradaban Jawa ramah dan toleran terhadap budaya dan peradaban lain. Bahkan kemudian 'bersedia' untuk bersinergi dan sampaipun ke masalah laku budaya spiritual. Dan sinergi tersebut akhirnya menghasilkan sinkretisme. Penyebaran agama Islam di tanah Jawa pada abad ke-15 dihadapkan kepada dua jenis lingkungan, yaitu budaya kejawen (istana Majapahit) yang menyerap unsur-unsur Hindunisme dan budaya pedesaan. Dalam pada itu terjadi culture contact yang kemudian berbuah akulturasi antara dua arus nilai yang sama besarnya, yaitu asimilasi antara ajaran Islam dengan budaya Jawa, baik dalam lingkungan keraton maupun pedesaan.

Secara etimologis, sinkretisme berasal dari kata syin dan kretiozein atau kerannynai, yang berarti mencampurkan elemen-elemen yang saling bertentangan. Adapun pengertiannya adalah suatu gerakan di bidang filsafat dan teologi untuk menghadirkan sikap kompromi pada hal yang agak berbeda dan bertentangan.Simuh menambahkan bahwa sinkretisme dalam beragama adalah suatu sikap atau pandangan yang tidak mempersoalkan murni atau tidaknya suatu agama. Oleh karena itu, mereka berusaha memadukan unsur-unsur yang baik dari berbagai agama, yang tentu saja berbeda antara satu dengan yang lainnya, dan dijadikannya sebagai satu aliran, sekte, dan bahkan agama.

Menurut Sumanto al-Qurtubi, "proses sinkretisme menjadi tak terelakkan ketika terjadi perjumpaan dua atau lebih kebudayaan/tradisi yang berlainan". Dalam menerangkan keberagaman masyarakat Jawa, Kuncaraningrat membagi mereka menjadi dua, yaitu agama Islam Jawa dan agama Islam Santri. Yang pertama kurang taat kepada syariat dan bersikap sinkretis yang menyatukan unsur-unsur pra-Hindu, Hindu, dan Islam, sedangkan yang kedua lebih taat dalam menjalankan ajaran agama Islam dan bersifat puritan.Namun demikian, meski tidak sekental pengikut agama Islam Jawa dalam keberagamaan, para pemeluk Islam santri juga masih terpengaruh oleh animisme, dinamisme, dan Hindu-Budha.

Dalam sejarah primbon agama di Jawa. Suku Jawa sebelum menerima pengaruh agama dan kebudayaan Hindu, masih dalam taraf animisme dan dinamisme. Mereka memuja roh nenek moyang dan percaya adanya kekuatan gaib atau daya magis yang terdapat pada benda, tumbuh-tumbuhan, bintang, dan lain-lain yang dianggap memiliki daya sakti. Kepercayaan dan pemujaan seperti tersebut di atas, dengan sendirinya belum mewujudkan diri sebagai suatu agama secara nyata dan sadar. Pemikiran yang seperti itu tidak mudah dihilangkan dalam kehidupan masyarakat jawa. Karena itu merupakan suatu kepercayaan. Bahkan pengaruhnya dalam kehidupan saat ini banyak yang masih digunakan sebagai pedoman, karena begitu kuatnya budaya orang jawa. 
Banyak sekali cerita di Jawa yang menggambarkan bahwa pemenuhan harapan orang kejawen tidak cukup hanya dengan bekerja dan bersembahyang. Ada upaya lain yang harus mereka lakukan. Upaya tersebut adalah ritual, yang dilaksanakan masyarakat sesuai dengan kepercayaan mereka terhadap berbagai mitos dan sejarah tempat-tempat keramat tertentu yang berkembang. Salah satu tempat ritual dan memiliki kepercayaan mitos yang kuat salah satunya adalah masyarakat Desa Bajulan Kecamatan Loceret Kabupaten Nganjuk.

Desa Bajulan terletak di Kecamatan Loceret Kabupaten Nganjuk. Banyak orang yang menganggap, bahwa Desa Bajulan sangat berkaitan dengan hal-hal mistis seperti ritual-ritual kejawen yaitu nyadranan, bersih desa, upacara parna prahista, kirab pusoko dan arca, ritual malem syuro, ritual pengambilan air suci, ritual mandi di air sumber,sarana lelaku ritual/meditasi, upacara ngangsu kaweruh, dan lain-lain. Ritual-ritual tersebut tidak lepas dari kepercayaan Kejawen, seperti solat sambil duduk, tidak melaksanakan puasa ramadhan tetapi ikut hari raya dan lain-lain. Sehingga disini peneliti ingin mengetahui bagaimana kepercayaan kejawen mempengaruhi agama khususnya agama Islam, bagaimana masyarakat mempercayai ritual tersebut dan sejauh apa mereka mempraktekkan apa yang mereka percayai, dan lain-lain.

Sehingga berdasarkan rasa ingin tahu yang tinggi peneliti melakukan penelitian dengan terjun langsung untuk mengamati fenomena yang terjadi disana berdasarkan apa yang telah menjadi spesifikasi tujuan pengamatan peneliti. Penelitian ini dilakukan di wilayah Nganjuk. Pemilihan dan penetapan lokasi ini dengan beberapa pertimbangan yaitu: Pertama, sebagian besar masyarakat Desa Bajulan masih mengamalkan nilainilai kejawen, yang kadang justru bertentangan dengan nilai-nilai syariat agama Islam. Kedua, kurangnya pembinaan dari instansi terkait, sehingga terkesan adanya pembiaran. Ketiga, dinamika stratifikasi sosial masyarakat setempat sering heterogen (atas, menengah dan bawah)/perbedaan kasta atau strata sosial, sehingga semakin menguatkan perbedaan satu dengan yang lainnya. Keempat, sebagai orang yang dibesarkan dekat dengan lokasi penelitian, peneliti ingin menyumbangkan pemikiran untuk membantu mensinergikan nilai keagamaan dengan kearifan budaya lokal masyarakat setempat. Kelima, lokasi penelitian mudah yang dijangkau oleh peneliti, sehingga keakraban peneliti dengan subjek penelitian mudah terjalin dengan baik.

\section{HASIL DAN PEMBAHASAN}

Bentuk Kegiatan Islam Kejawen dan Pemecahannya dalam Perspektif Agama dalam Mewujudkan dan Menciptakan Lingkungan yang Madani di Wilayah Nganjuk

Bentuk-bentuk kegiatan ritual Islam kejawen di antaranya sebagai berikut:

\section{Upacara Pernikahan}

Upacara pernikahan di Desa Bajulan Kecamatan Loceret Kabupaten Nganjuk umumnya diselenggarakan secara besar-besaran, khususnya pada pihak mempelai wanita. Beberapa hari sebelum perayaan pernikahan keluarga serta para kerabat sudah disibukkan dengan banyak hal yang berkaitan dengan persiapan upacara tersebut. Banyak ritual yang dilakukan dalam upacara ini. Di antaranya slametan menjelang pesta pernikahan (kenduri),siraman, midadareni, upacara pernikahan yang di dalamnya terdapat banyak ritual seperti mbalangsuruh, midhak endhog,kacar-kucur, dan lain sebagainya, selain itu adapula slametan sesudah upacara pernikahan atau upacara boyongan.

\section{Upacara Tingkeban atau Mitoni}

Upacara tingkeban atau mitoni ini merupakan upacara yang sangat penting bagi masyarakat Jawa. Upacara ini dilangsungkan pada saat usia kandungan ibu hamil berumur tujuh bulan. Di Desa Bajulan Kecamatan Loceret Kabupaten Nganjuk, upacara ini biasanya diadakan pada hari yang mereka anggap baik yaitu pada hari rabu atau hari sabtu dan tanggalnyapun harus tanggal yang ganjil sebelum tanggal 15 Jawa.

Bagi masyarakat Desa Bajulan Kecamatan Loceret Kabupaten Nganjuk, upacara ini dimaksudkan sebagai bentuk rasa syukur kepada Allah SWT dan semoga janin yang dikandung oleh sang ibu bisa selalu sehat sampai saat kelahiran nanti. Selain itu upacara tingkeban ini dimaksudkan sebagai suatu peringatan 
bahwa usia kehamilan sudah mencapai tujuh bulan, itu berarti sang ibu dan keluarga harus lebih mempersiapkan segala sesuatu yang berkaitan dengan sang calon bayi tersebut.

\section{Upacara kelahiran}

Di Desa Bajulan Kecamatan Loceret Kabupaten Nganjuk, sehari setelah kelahiran bayi mereka mengadakan kenduren atau sering dinamakan slametanbrokohan. Slametan brokohan ini mempunyai maksud sebagai ungkapan rasa syukur yang teramat dalam kepada Allah karena bayi dapat lahir dengan selamat dan ibu sang bayi juga diberi kesehatan.

Bagi masyarakat Desa Bajulan Kecamatan Loceret Kabupaten Nganjuk upacara kelahiran merupakan salah satu bentuk rasa syukur kepada Allah SWT karena bayi dapat lahir dengan selamat dan ibu sang bayi juga diberi kesehatan. Sehari setelah kelahiran bayi mereka mengadakan kenduri atau sering dinamakan slametanbrokohan. Kemudian setelah itu, lima hari setelah kelahiran bayi mereka mengadakan upacara sepasaran bayi. Pada upacara sepasaran bayi ini, mereka memberikan nama bagi sang bayi. Karena masyarakat Desa Bajulan mayoritas muslim, maka mereka juga mengadakan upacara penyembelihan hewan aqiqah.

\section{Upacara Sunatan atau Khitanan}

Upacara sunatan atau khitanan ini dilakukan pada saat anak berusia 12 sampai 14 tahun. Di Desa Bajulan Kecamatan Loceret Kabupaten Nganjuk, upacara ini biasanya dilaksanakan secara besar-besaran. Hal ini mereka maksudkan sebagai pemberitahuan kepada masyarakat bahwa ia sudah baligh. Selain itu upacara khitanan ini mereka maksudkan sebagai bentuk perwujudan tentang pelaksanaan hukum Islam.

\section{Upacara Kematian}

Bagi masyarakat Jawa pada umumnya dan masyarakat Desa Bajulan Kecamatan Loceret Kabupaten Nganjuk pada khususnya, upacara kematian ini merupakan upacara yang sama sekali tidak dapat ditinggalkan. Kecuali bagi mereka yang mempunyai keyakinan bahwa upacara kematian tidak perlu dilaksanakan.

Upacara kematian merupakan bentuk penghormatan terakhir kepada arwah yang sudah meninggal. Setelah segala prosesi pemakaman terlaksana, maka pihak keluarga mengadakan slametan geblak,mitungdina (tujuh hari), matangpuluhdina (empat puluh hari), nyatus (seratus hari) mendak sepisan (satu tahun), mendak panda (dua tahun) dan yang terakhir nyewu (seribuhari) atau biasa disebut dengan slametannguwis-uwisi.

\section{Nyadran}

Upacara nyadran ini dilaksanakan pada pertengahan bulan Ruwah (dalam kalender Jawa), dan Sya'ban (dalam kalender Hijriyah) yaitu antara tanggal 15 sampai menjelang bulan Ramadhan. Di Desa Bajulan Kecamatan Loceret Kabupaten Nganjuk, upacara nyadran biasanya dilaksanakan di makam. Masyarakat berbondong-bondong datang ke makam dengan membawa berbagai macam makanan. Dan makanan-makanan ini biasanya ditempatkan di tampah (yaitu suatu wadah yang terbuat dari anyaman bambu). Setelah mereka berkumpul, kemudian salah satu di antara mereka yang mereka anggap sebagai kyai memimpin untuk membaca tahlil dan do'a bersama.

\section{Bersih desa}

Upacara bersih desa di Desa Bajulan Kecamatan Loceret Kabupaten Nganjuk dilaksanakan sekali dalam setahun dan melibatkan semua warga lelaki. Mereka melakukan bersih-bersih desa dan makam. Hal itu dimaksudkan agar desa menjadi lebih bersih dan lebih indah dipandang.

Upacara bersih desa dilaksanakan satu kali dalam satu tahun dan melibatkan semua warga lelaki. Mereka melakukan bersih-bersih desa dan makam. Dan setelah selesai bersih-bersih, mereka makan bersama di sekitar makam. Selain dimaksudkan agar desa menjadi lebih bersih dan lebih indah dipandang, hal tersebut juga mereka maksudkan untuk memupuk rasa kebersamaan. 


\section{Upacara peringatan hari lahir Nabi Muhammad Saw.}

Upacara ini dilaksanakan pada tanggal 12 bulan Maulud, disebut muludan. Untuk memperingatinya, biasanya di Desa Bajulan mengadakan slametan kenduri. Slametan ini dimaksudkan untuk memperingati hari lahir Nabi Muhammad Saw. Upacara ini dilaksanakan pada tanggal 12 bulan Maulud, dan biasa disebut slametanmuludan. Slametan ini dimaksudkan untuk memperingati hari lahir Nabi Muhammad Saw. serta bentuk penghormatan terhadap Nabi Muhammad Saw.

\section{Upacara Nifsu Sya'ben pada pertengahan bulan Sya'ban (Ruwah)}

Upacara ini biasanya dilaksanakan pada pertengahan bulan Sya'ban (kalender Hijriyah) dan bulan Ruwah (kalender Jawa) antara tanggal 15 sampai dengan menjelang bulan Ramadhan. Di Desa Bajulan Kecamatan Loceret Kabupaten Nganjuk selain mengadakan upacara bersih desa dan nyadran, biasanya mereka mengadakan slametan kenduri yang biasa disebut dengan ruwahan, dengan menu sajian apem, ketan, kolak, nasi beserta lauk, serta buah-buahan.

Metode untuk Menyinergikan Nilai Keagamaan dengan Kearifan Budanya Lokal, dalam Perspektif Agama dalam Mewujudkan dan Menciptakan Lingkungan yang Madani di Wilayah Nganjuk

Metode untuk menyinergikan nilai keagamaan dengan kearifan budanya lokal dalam perspektif agama dalam mewujudkan dan menciptakan lingkungan yang madani di Desa Bajulan Kecamatan Loceret Kabupaten Nganjuk adalah dengan cara sebagai berikut:

\section{Dakwah Bil Hal}

Kegiatan dakwah bilhal bisa menjadi faktor pendorong masyarakat untuk memberikan respon baik terhadap kehadiran da'i dan ajaran Islam di kalangan masyarakat. Kegiatan dakwah seperti ini pula yang sering digunakan oleh da'i dalam kehidupan bermasyarakat. Dengan metode seperti ini, diharapkan Islam semakin bisa diterima kehadirannya di tengah-tengah warga masyarakat.

\section{Merintis Kegiatan Islami}

Kegiatan lain yang dilakukan untuk menyinergikan nilai keagamaan dengan kearifan budanya lokal dalam perspektif agama dalam mewujudkan dan menciptakan lingkungan yang madani di Desa Bajulan Kecamatan Loceret Kabupaten Nganjuk adalah dengan merintis kegiatan Islami. Hal ini bertujuan agar masyarakat tertarik dan bisa mengenal Islam dengan lebih baik.

\section{Peringatan Hari Besar Islam (PHBI)}

Peringatan hari besar Islam (PHBI) merupakan kegiatan untuk membangkitkan semangat keIslaman di kalangan masyarakat Desa Bajulan Kecamatan Loceret Kabupaten Nganjuk. Kegiatan ini biasanya dilaksanakan satu tahun sekali, sesuai dengan penanggalan hijriyah. Seperti acara Mauludan, Isra' Mi'raj, Rajabiah, dan tentunya tahun baru Hijriyah 1 Muharam atau suronan dalam kepercayaan masyarakat Desa Bajulan Kecamatan Loceret, karena perhitungan pada penanggalan Jawa sama dengan penanggalan Hijriyah.

\section{Pendidikan Agama Islam}

Kegiatan pendidikan agama Islam yang dilakukan Desa Bajulan Kecamatan Loceret Kabupaten Nganjuk di desa Desa Bajulan Kecamatan Loceret Kabupaten Nganjuk, yaitu dengan cara mendirikan lembaga pendidikan Islam. Para tokoh ormas NU di Desa Bajulan Kecamatan Loceret mendirikan lembaga pendidikan Madrasah Ibtidaiyah (MI). tujuan didirikan MI ini adalah untuk memberikan pendidikan dasar bagi anak-anak di Desa Bajulan Kecamatan Loceret Kabupaten Nganjuk.

\section{Strategi Infiltrasi Budaya}

Strategi infiltrasi budaya merupakan sebuah strategi dengan cara penyusupan unsur budaya. Bentuk penyusupan ajaran Islam yang sengaja maupun tidak sengaja, merasuk dan mempengaruhi diri pada anggota komunitas masyarakat di Desa Bajulan Kecamatan Loceret Kabupaten Nganjuk, sedangkan 
yang menjadi sasaran dakwah atau tidak dikhususkan sebagai sasaran, tetapi masuk dalam sistem budaya pada masyarakat di Desa Bajulan Kecamatan Loceret Kabupaten Nganjuk.

\section{Strategi Ta'lim atau Pendidikan}

Penerapan strategi ta'lim terlihat dalam pendirian lembaga pendidikan Islam yang meliputi; Madrasah Ibtidaiyah (MI) dan Taman Pendidikan Al-Qur'an (TPQ). Pelaksanaan kegiatan dakwah menerapkan proses yang sistematis melalui lembaga pendidikan Islam. Untuk menyinergikan nilai keagamaan dengan kearifan budanya lokal dalam perspektif agama dalam mewujudkan dan menciptakan lingkungan yang madani bersifat tetap.

\section{Strategi Sentimentil}

Strategi untuk menyinergikan nilai keagamaan dengan kearifan budanya lokal dalam perspektif agama dalam mewujudkan dan menciptakan lingkungan yang madani yang memfokuskan pada aspek hati untuk berusaha menggerakkan perasaan dan batin Strategi ini dilakukan dengan memberi nasihat yang mengesankan, memanggil dengan kelembutan, atau memberikan pelayanan yang memuaskan kepada masyarakat.

Penerapan Metode untuk Menyinergikan Nilai Keagamaan dengan Kearifan Budanya Lokal dalam Perspektif Agama dalam Mewujudkan dan Menciptakan Lingkungan yang Madani di Wilayah Nganjuk

Penerapan metode untuk menyinergikan nilai keagamaan dengan kearifan budanya lokal dalam perspektif agama dalam mewujudkan dan menciptakan lingkungan yang madani di Desa Bajulan Kecamatan Loceret Kabupaten Nganjuk sebagai berikut:

\section{Dakwah Bil Hal}

Kegiatan dakwah bilhal kegiatan yang berupa pemberian contoh secara langsung kepada masyarakat. Da'i ikut berperang aktif dalam kehidupan bermasyarakat sehari-hari, tanpa ada batasan dengan warga lainnya.

\section{Merintis Kegiatan Islami}

Kegiatan merintis kegiatan Islami sudah dilakukan oleh da'i cukup lama. Da'i memanfaatkan kegiatan organisasi masa keagamaan yang telah berlangsung rutin di masyarakat. Pemanfaatan ini berbentuk penyisipan kegiatan Islami ke dalam kegiatan rutin ormas keagamaan tersebut. Dalam hal ini, ormas yang dimaksud adalah NU dan Muslimat NU. Sedangkan kegiatan Islami yang disisipkan adalah barjanzian, yasinan, tahlilan, dan mau'idhoh hasanah.

\section{Peringatan Hari Besar Islam (PHBI)}

Dalam kegiatan pengajian umum yang biasa dilakukan oleh warga dalam rangka peringatan hari besar Islam merupakan salah satu bentuk perwujudan penerapan strategi tilawah. Di mana mitra dakwah diminta untuk mendengarkan penjelasan materi dakwah yang disampaikan. Penerapan strategi ini merupakan transfer pesan dakwah dengan lisan dan tulisan. Strategi tilawah lebih banyak mengarah pada ranah kognitif (pemikiran) yang transformasinya melewati indra pendengaran dan indra penglihatan serta ditambah akal yang sehat yang ada pada masyarakat.

\section{Pendidikan Agama Islam}

Pelaksanaan kegiatan merintis kegiatan Islami, terjadi hubungan timbal balik yang baik antara da'i dengan organisasi masa yang ada di Desa Bajulan Kecamatan Loceret Kabupaten Nganjuk. Da'i merintis kegiatan_kegiatan Islami untuk menjadi kegiatan yang disenangi masyarakat Desa Bajulan Kecamatan Loceret Kabupaten Nganjuk. Dalam melaksanakan kegiatan dakwah, da'i melihat dari sisi peluang 
dakwah yang dapat dilakukan berdasar kondisi masyarakat setempat. Dengan begitu, kegiatan-kegiatan yang dilakukan da'i lebih mudah diterima kehadirannya oleh warga setempat.

\section{Pembentukan dirasah Islamiyah untuk orang tua}

Membentuk dirosah kusus orang dewasa di Desa Bajulan dilakukan bertujuan untuk mengajak warga masyarakat Desa Bajulan untuk beriman, bertaqwa serta menta'ati segala perintah Allah dan Rasul, melaksanakan amar ma'ruf nahi munkar, memperbaiki dan membangun masyarakat yang Islami, menegakkan serta menyiarkan agama Islam dan proses penyelenggaraan merupakan usaha untuk mencapai tujuan yakni kebahagiaan dan kesejahteraan hidup dunia dan akhirat.

\section{Istighosah}

Istighosah adalah menghadiri suatu majelis untuk melaksanankan ibadah, do'a, bersholawat dan dzikir yang bermanfaat untuk memohon bantuan, minta pertolongan kepada Allah SWT. atas segala sesuatu yang dihadapi. Dengan demikian dapat disimpulkan bahwa makna istighosah adalah menghadiri suatu majlis untuk melaksanakan ibadah, do'a, zikir, dan bersholawat bersama yang bermanfaat untuk memohon bantuan, minta pertolongan kepada Allah SWT. atas segala sesuatu yang dihadapi manusia yang dipimpin oleh orang alim atau orang yang berilmu. Dalam istighosah di sini juga dilaksanakan ibadah shalat sunah tasbih yang dikerjakan sebelum melaksanakan do'a, zikir, dan shalawat bersama. Sholat sunah tasbih dilaksanakan dua minggu sekali dalam pelaksanaan istighosah.

\section{Kegiatan praktek shalat}

Shalat adalah perintah Allah dan wajib dilaksanakan bagi setiap orang muslim. Shalat adalah kunci menuju surga. Sebab semua makhluk adalah ciptaan Allah SWT, maka sebagai perwujudan keimanan terhadap Allah kita harus melaksanakan shalat. Kewajiban shalat bisa dilakukan secara langsung kalau shalat adalah perintah Allah yang harus dikerjakan setiap orang Islam, menjelaskan hukum-hukum shalat serta bacaan-bacaan yang terkandung di dalamnya.

\section{PENUTUP}

Berdasarkan penelitian yang telah dilakukan tentang mensinergikan nilai-nilai keagamaan dengan kearifan lokal sebagai upaya mewujudkan masyarakat madani di Desa Bajulan Kecamatan Loceret Kabupaten Nganjuk, maka dapat disimpulkan: (1) Perilaku kejawen ialah perilaku yang dijiwai oleh nilai-nilai budaya Jawa, yang pada sebagian besar telah dipengaruhi oleh ajaran Islam (mistik Islam). Adapun bentuk-bentuk kegiatan Islam kejawen di Desa Bajulan Kecamatan Loceret Kabupaten Nganjuk di antaranya adalah upacara pernikahan, upacara tingkeban atau mitoni, upacara kelahiran, upacara sunatan atau khitanan, upacara kematian, nyadran, bersih desa, upacara peringatan hari lahir Nabi Muhammad Saw., dan upacara nifsu sya'ban pada pertengahan bulan sya'ban (ruwah). (2) Metode untuk menyinergikan nilai keagamaan dengan kearifan budanya lokal dalam perspektif agama dalam mewujudkan dan menciptakan lingkungan yang madani di Desa Bajulan Kecamatan Loceret Kabupaten Nganjuk adalah dengan cara sebagai berikut dakwah bil hal, merintis kegiatan Islami, Peringatan Hari Besar Islam (PHBI), pendidikan agama Islam, strategi infiltrasi budaya, strategi ta'lim atau pendidikan, dan strategi sentimentil. (3) Penerapan metode untuk menyinergikan nilai keagamaan dengan kearifan budanya lokal dalam perspektif agama dalam mewujudkan dan menciptakan lingkungan yang madani di Desa Bajulan Kecamatan Loceret Kabupaten Nganjuk dengan cara menerapkan dakwah bil hal, merintis kegiatan Islami, Peringatan Hari Besar Islam (PHBI), pendidikan agama Islam, pembentukan dirasah Islamiyah untuk orang tua, istighosah, dan kegiatan praktek shalat. Dengan penerapan metode tersebut, diharapkan menjadikan Islam sebagai agama mayoritas bisa diterima oleh masyarakat Desa Bajulan Kecamatan Loceret Kabupaten Nganjuk. Akan tetapi penyampaian dengan menggunakan cara tersebut menimbulkan kurangnya pemahaman mengenai ajaran Islam, sehingga sikap masyarakat banyak yang masih melaksanakan tradisi kejawen. Sikap demikian membuat agama Islam belum secara penuh menjadi pedoman hidup seutuhnya. 


\section{DAFTAR RUJUKAN}

Abdullah, Abd. Rahman. (2011). Aktualisasi Konsep Dasar Pendidikan Islam: Rekonstruksi Pemikiran dalam Tinjauan Filsafat Pendidikan Islam. Yogyakarta: UII Press.

Adhim, Muhammad Fauzi. (2012). Pendidikan Anak Menuju Taklif. Yogyakarta: Pustaka Pelajar.

Affandy, Didied dan Putu Wulandari. (2012). An Expliration Local Wisdom Priority in Public Budgeting Process ol Local Government. Jakarta: Rineka Cipta.

Ahmad, Haidlor Ali. (2010). Kearifan Lokal sebagai Landasan Pembangunan Bangsa. Bandung: Remaja Rosdakarya.

Ahmadi, Abu. (2011). Psikologi Perkembangan. Jakarta: Rineka Cipta.

Aman,Syaifuddin. (2010). Membangun Masyarakat Madani. Jakarta: Mwardi Prima.

Arifin, Mike S. (1996). Orientasi Teoritik dan Memilih Pokok Studi: Jenis Studi Kasus dalam Penelitian Kualitatif, dalam Penelitian Kualitatif dalam Ilmu-ilmu Sosial dan Keagamaan. Malang: Kalimasahada Press.

Arikunto, Suharsimi. (2013). Prosedur Penelitian: Suatu Pendekatan Praktek. Jakarta: Rineka Cipta.

Asriati, Nuraini. (2012). Mengembangkan Karakter Peserta Didik Berbasis Kearifan Lokal Melalui Pembelajaran di Sekolah. Jakarta: Gunung Agung.

Azra, Azzumardi. (2012). Menuju Masyarakat Madani: Gagasan Fakta dan Tantangan. Jakarta: Raja Grafindo Persada.

Bogdan, R.C. dan Biklen, S.K. (1989). Qualitative Research for Education: An Introduction to Theory and Methods. Boston: Aliyn dan Bacon.

Branson, Margaret S. (2012). Belajar Civic Education dari Amerika. Yogyakarta: LKIS.

Cresswell J.W. (1995). Research Desain Qua! it at jf and Quantitative Apprpoachess. Thousand, oaks, London, New delhi: SAGE, Publications.

Culla, Adi Suryadi. (2004). Masyarakat Madani: Pemikiran, Teori dan Relevansinya dengan Cita-cita Reformasi. Jakarta: Raja Grafindo Persada.

Daradjat, Zakiyah. (2010). Ilmu Jiwa Agama. Jakarta: Bulan Bintang.

Daradjat, Zakiyah. (2012). Peranan Agama dalam Kesehatan Mental. Jakarta: Gunung Agung.

Daradjat, Zakiyah. (2013). Dasar-dasar Agama Islam. Jakarta: Bulan Bintang.

Departemen Agama RI. (2011). Al-Qur'an dan Terjemahnya. Jakarta: Proyek Pengadaan Kitab Suci AlQur'an.

Gazalba, Sidi. (2011). Masjid Pusat Ibadat dan Kebudayaan Islam. Jakarta: Pusat Antara.

Hariyadi dkk. (2012). Etika Islam Universal dan Budaya Lokal. Salatiga: STAIN Salatiga Press.

Hasanuddin, A. (2012). Cakrawala Kuliah Agama. Surabaya: Al-Ikhlas.

Hendropuspito. (2013). Sosiologi Agama. Yogyakarta: Yayasan Yanisius.

Hikam, Muhammad A.S. (2011). Demokratisasi dan Pemberdayaan Civil Society. Surabaya: Erlangga.

Huwaidi, Fahmi. (2012). Demokrasi Oposisi dan Masyaraka Madani. Jakarta: Gunung Agung.

Jalaluddin. (2010). Psikologi Agama. Jakarta: Raja Grafindo Persada.

Khalil, Ahmad. (2012). IslamJawa dalam Etika dan Tradisi Jawa. Malang: UIN Malang Press.

Koentjoroningrat. (2013). Metode Wawancara dalam Metode-metode Penelitian Masyarakat. Jakarta: Gramedia Pustaka Utama.

Madjid, Nurcholish. (2012). Masyarakat Tamaddun: Kritik Hermeneutis Masyarakat Madani. Jakarta: Raja Grafindo Persada.

Magdalia, Alfian. (2013). Potensi Kearifan Lokal dalam Pembentukan Jati Diri dan Karakter Bangsa. Jakarta: FIPB UI.

Misbeth, SJ. dan J. Watt. (1994). Studi Kasus Sebuah Panduan Praktiis. Jakarta: Gramedia: Widia Sarana Indonesia.

Moleong, Lexy J. (2012). Metodologi Penelitian Kualitatif. Bandung: Remaja Rosdakarya.

Muhanjir, Noeng. (2010). Metodologi Penelitian Kualititif. Yogyakarta: Rake Sarasin.

Mungmachon, Roikhwanphut. (2012). Knowledge and Local Wisdom. Bandung: Remaja Rosdakarya.

Nasution, S. (1995). Met ode Research Penelitian Ilmiah. Jakarta: Bumi Aksara.

Nasution, S. (1998). Metode Penelitian Naturalistik dan Kualitatjf. Bandung: Tarsono.

Nur'aeni. (2010). Interaksi Dini Bagi Anak Bermasalah. Jakarta: Rineka Cipta.

Nurdin, Muslim dkk. (2013). Moral dan Kognisi Islam: (Buku Teks Agama Islam Untuk Perguruan Tinggi Umum). Bandung: Alfabeta.

Poerwadarminta, WJS. (2014). Kamus Besar Bahasa Indonesia. Jakarta: Raja Grafindo Persada.

Prasetyo, Hendro dan Ali Munhany. (2012). Islam Civil Society: Pandngan Muslim Indonesia. Jakarta: Gramedia Pustaka Utama. 
Prasetyo, Zuhdan K. (2013). Pembelajaran Sains Berbasis Kearifan Lokal. Surakarta, FKIP UNS.

Pusat Pembinaan dan Pengembangan Bahasa. (2010). Kamus Besar Bahasa Indonesia. Jakarta: Balai Pustaka.

PUSLIT IAIN Syarif Hidayatullah. (2013). Pendidikan Kewargaan, Demokrasi, HAM danMasyarakat Madani. Jakarta: IAIN Press.

Rais,Amin. (2013). Siasat Gerakan Kota Jalan Menuju Masyarakat Baru. Yogyakarta: Salahuddin.

Razak, Nazaruddin. (2013). Dienul Islam. Bandung: Alma’arif.

Rini, Puspa dan Siti Czafrani. (2013). Pengembangan Ekonomi Kreatif Berbasis Kearifan Lokal. Bandung: Remaja Rosdakarya.

Rizal, Nasruddin. (2013). Dienul Islam. Bandung: Al-Ma'arif.

Roibin. (2011). Relasi Agama dan Budaya Masyarakat Kontemporer,. Malang: UIN Malang Press.

Rusdi, Farid. (2012). Menggagas Pencitraan Berbasis Kearifan Lokal. Bandung: Remaja Rosdakarya.

Sartini, Wayan. (2013). Menggali Nilai Kearifan Lokal Budaya Jawa Lewat Ungkapan: (Bebasan, Saloka, dan Paribasan). Surabaya: Usaha Nasional.

Setiyadi, Putut. (2012). Pemahaman Kembali Local Wisdom Etnik Jawa dalam Tembang Macapat dan Pemanfaatannya sebagai Media Pendidikan Budi Pekerti Bangsa. Jakarta: Raja Grafindo Persada.

Shodiq, Ja'far. (2008). Pertemuan antara Tarekat dan NU. Yogyakarta: Alumi.

Sitorus. (1998). Penelitian Kualitatatif Suatu Perkenalan. Bogor: Kelompok Dokumentasi Ilmu Sosial, Jurusan limu-Ilmu Sosial dan Ekonomi Pertanian. Fakultas Pertanian Institut Pertanian Bogor.

Steenbrink, Karel A. (2014). Pesantren, Madrasah, Sekolah Pendidikan Islam dalam kurun Moderen. Jakarta: Pustaka LP3ES Indonesia.

Sukardi, Dewa Ketut. (1985). Pengantar Teori Konseling: (Suatu Uraian Ringkas). Jakarta: Ghalia Indonesia. Sukri, Sri Suhandjati. (2004). Ijtihad Progresif Yadasipura II. Yogyakarta: Alumni.

Suprayogo, Imam dan Tabrani. (2011). Metodologi Penelitian Kualitatif. Bandung: Remaja Rosdakarya.

Sutarso, Joko. (2013). Menggagas Pencitraan Berbasis Kearifan Lokal. Bandung: Remaja Rosdakarya.

Suwondo, Kutut. 2013. Civil Society di Aras Lokal. Salatiga: Yayasan Percik.

Syamsuddin, M. Din. (2013). Etika Agama dalam Membangun Masyarakat Madani. Jakarta: Rineka Cipta.

Tilaar, H.A.R. (2010). Pendidikan, Kebudayaan dan Masyarakat Madani Indonesia. Jakarta: Rineka Cipta.

Ulwan, Abdullah Nasih. (2012). Pendidikan Anak menurut Islam Kaidah-kaidah Dasar. Bandung: Remaja Rosdakarya.

Umari, Akram Dhiyauddin. (2010). Masyarakat Madani: Tinjauan Historis Kehidupan Zaman Nabi. Jakarta: Rineka Cipta.

Widjojo, Agus. (2011). Indonesia dalam Tradisi Menuju Demokrasi. Jakarta: Raja Grafindo Persada.

Yunus, Mahmud. (2012). Kamus Arab-Indonesia. Jakarta: Hidakarya Agung.

Yusuf, Syamsu. (2014). Psikologi Perkembangan Anak dan Remaja. Bandung: Remaja Rosdakarya.

Zaini, Syahminan. (2010). Hakekat Agama dalam Kehidupan Manusia. Surabaya: Al-Ikhlas.

Zamroni. (2011). Pendidikan, dan Demokrasi dalam Transisi: (Prakondisimenuju era Globalisasi). Jakarta: PSAP Muhammadiyah. 